\title{
Research
}

Natasha J Verbakel, Maaike Langelaan, Theo JM Verheij, Cordula Wagner and Dorien LM Zwart

\section{Effects of patient safety culture interventions on incident reporting in general practice:}

\author{
a cluster randomised trial
}

\begin{abstract}
Background

A constructive safety culture is essential for

the successful implementation of patient safety improvements.

\section{Aim}

To assess the effect of two patient safety culture interventions on incident reporting as a proxy of safety culture.

\section{Design and setting}

A three-arm cluster randomised trial was conducted in a mixed method study, studying the effect of administering a patient safety culture questionnaire (intervention I), the questionnaire complemented with a practice-based workshop (intervention II) and no intervention (control) in 30 general practices in the Netherlands.
\end{abstract}

\section{Method}

The primary outcome, the number of reported incidents, was measured with a questionnaire at baseline and a year after. Analysis was performed using a negative binomial model. Secondary outcomes were quality and safety indicators and safety culture. Mixed effects linear regression was used to analyse the culture questionnaires.

\section{Results}

The number of incidents increased in both intervention groups, to 82 and 224 in intervention I and II respectively. Adjusted for baseline number of incidents, practice size and accreditation status, the study showed that practices that additionally participated in the workshop reported 42 (95\% confidence interval $[\mathrm{Cl}]=9.81$ to 177.50 ) times more incidents compared to the control group. Practices that only completed the questionnaire reported 5 (95\% Cl $=1.17$ to 25.49$)$ times more incidents. There were no statistically significant differences in staff perception of patient safety culture at follow-up between the three study groups.

\section{Conclusion}

Educating staff and facilitating discussion about patient safety culture in their own practice leads to increased reporting of incidents. It is beneficial to invest in a team-wise effort to improve patient safety.

\section{Keywords}

general practice; improvement, intervention studies; patient safety; primary health care; safety culture.

\section{INTRODUCTION}

At the start of patient safety research, the Institute of Medicine states that "healthcare organizations must develop a culture of safety to focus on improving the reliability and safety of care for patients." Originating from organisational culture, safety culture is described as the product of individual and group values, attitudes, perceptions, competencies, and patterns of behaviour that determine the commitment to, and the style and proficiency of, an organisation's health and safety management. ${ }^{2}$ Patient safety culture in general practice concerns matters such as (daring to) speak up and address each other and reporting and learning from incidents.

In the Netherlands, patient safety policy in general practice is being developed and among other reasons there was a clear need for effective intervention tools on safety culture. A patient safety culture questionnaire is available for general practice and is one of the optional modules in the accreditation process. There are no national incentives, contractual or financial, to engage practices in patient safety culture interventions. Two reviews examining culture improvement strategies in hospitals showed broad multi-part interventions and walk rounds with engaged leaders to be most successful.,4, (A walk round is a way to engage senior leaders in safety [culture]

NJ Verbakel, patient safety researcher; TJM Verheij, GP, professor of general practice; DLM Zwart, GP, head of students education of general practice, associate professor, Department of General Practice, Julius Center for Health Sciences and Primary Care, University Medical Center Utrecht, Utrecht, The Netherlands. M Langelaan, patient safety researcher, Nivel, Netherlands Institute for Health Services Research, Utrecht, The Netherlands.

C Wagner, professor of patient safety, EMGO+ Institute, Department of Public and Occupational Health, VU University Medical Center, Amsterdam, The Netherlands. issues. Senior leaders, clinicians and other staff perform regular rounds where they discuss patient safety items directly at the shop floor). Although a large part of health care is delivered in primary care, a review resulted in only few studies on interventions affecting its culture. ${ }^{5}$

Surveys, initially developed to measure existing culture, ${ }^{6-10}$ have been observed to possibly affect aspects of safety culture, ${ }^{3,11,12}$ by increasing risk awareness and, to a lesser extent, contributing to awareness of issues surrounding patient safety. Administering a survey draws attention to the topic, influencing staff and as such can be considered an intervention. ${ }^{13,14}$ The advantage of a survey is the usability and relatively low cost, however, when considering it as a safety culture intervention, it is questionable whether it is strong enough to accomplish sustained changes on it own. Indeed, the effectiveness of a survey as a tool for change is determined by the process of digesting and reporting the data. ${ }^{13}$

In addition, educational activities, such as workshops, showed positive results on risk management and safety culture. ${ }^{15,16}$ The Manchester Patient Safety Framework (MaPSaF) is a discussion tool for assessing and improving the maturity of safety culture in primary care setting $s^{17}$ and is increasingly being used. ${ }^{18-20}$

\section{Address for correspondence}

Dorien Zwart, Julius Center, P.O. Box 85500, 3508 GA Utrecht The Netherlands.

E-mail: d.zwartवumcutrecht.nl

Submitted: 7 March 2015; Editor's response: 9 March 2015; final acceptance: 9 March 2015 @British Journal of General Practice

This is the full-length article (published online 27 Apr 2015) of an abridged version published in print. Cite this version as: Br J Gen Pract 2015; DOI: 10.3399/bjgp15X684853 


\section{How this fits in}

Following hospitalised care, the focus on patient safety culture has reached general practice. A constructive patient safety culture is considered key in patient safety improvement efforts, however, to date, it is unknown which culture interventions are adequate for general practice. This study showed that administering a patient safety culture questionnaire raised awareness, but that the combination of such a questionnaire and a practice-based workshop was more successful in terms of increased incident reporting. This finding emphasises the importance of a team approach when implementing safety culture improvement interventions.

The aim of this study was to assess the effect of administering a culture questionnaire with digital feedback or the questionnaire combined with a practicebased workshop including feedback in general practice. It was hypothesised that both interventions would lead to improved perceptions of patient safety culture relative to the control practices, and that practices receiving the workshop would improve the most.

\section{METHOD}

\section{Design and participants}

A three-armed cluster randomised trial, in a mixed methods study was conducted. Randomisation was stratified based on practice size (small: <8 employees, large: $\geq 8$ employees), and accreditation status (Figure 1). The minimisation technique was used taking into account the strata, and was performed by the data management department independent of the research team. The practices were enrolled and contacted by the first author. Due to the nature of the interventions blinding was not possible. Details of the study protocol have been described previously. ${ }^{21}$

\section{Interventions}

Two interventions were studied: the administering of and feedback on a patient safety culture questionnaire (intervention I), the administering of the questionnaire complemented with a patient safety workshop (intervention II), and no intervention.

Patient safety culture questionnaire (intervention 1). The SCOPE questionnaire, translated and adapted originally from the
Hospital Survey on Patient Safety Culture (HSOPS) ${ }^{22}$ specifically for Dutch general practices $^{23}$ was used as the intervention tool. SCOPE is the Dutch acronym for systematic culture inquiry on patient safety. Practices simultaneously received a login for the SCOPE questionnaire and a key to download their results in a report. Practices were reminded twice to complete the questionnaire and to download their report. An online system was used for collection of the SCOPE data. ${ }^{24}$

Practice based patient safety workshop (intervention II). The workshop consisted of education on the concept of patient safety and culture, terminology, and human factor engineering. Appendix 1 shows the details of the workshop. Discussion about the own culture was facilitated using their own SCOPE results and Dutch translations of the $\mathrm{MaPSaF}^{17}$ focusing on two SCOPE dimensions that scored lowest. A discussion of possible improvements resulted in an action plan. The workshop was led by an independent GP trainer who was well-informed on the subject. It was held at practice location, lasted 3.5 hours, and attendance of $75 \%$ staff was required. Each practice received one workshop about 1-2 months after completing the SCOPE questionnaire, one practice received the workshop after 4 months. To study the course of the workshop one author attended and kept observations. Participants were also asked to complete an evaluation form.

\section{Outcome measurements}

Primary outcome. The primary outcome was the number of reported incidents per practice at follow-up, measured with a questionnaire. Contact persons were asked to report the number of incidents that were known from the year before the intervention and 1 year thereafter. If available they may have extracted this data from their intrapractice reporting system. Actual reporting is a prominent feature of a generative safety culture..$^{25}$ Because reporting is just in its infancy in general practice, ${ }^{26,27}$ it was hypothesised that an increase of reports would reflect a 'pattern of behaviour'2 congruent to improvement of patient safety culture. Hence, the number of incidents reported as a proxy of actual patient safety culture was considered.

Secondary outcome. Patient safety culture was additionally operationalised by quality and safety indicators (for example, the presence of complaints procedure, and patient safety being an agenda item of 


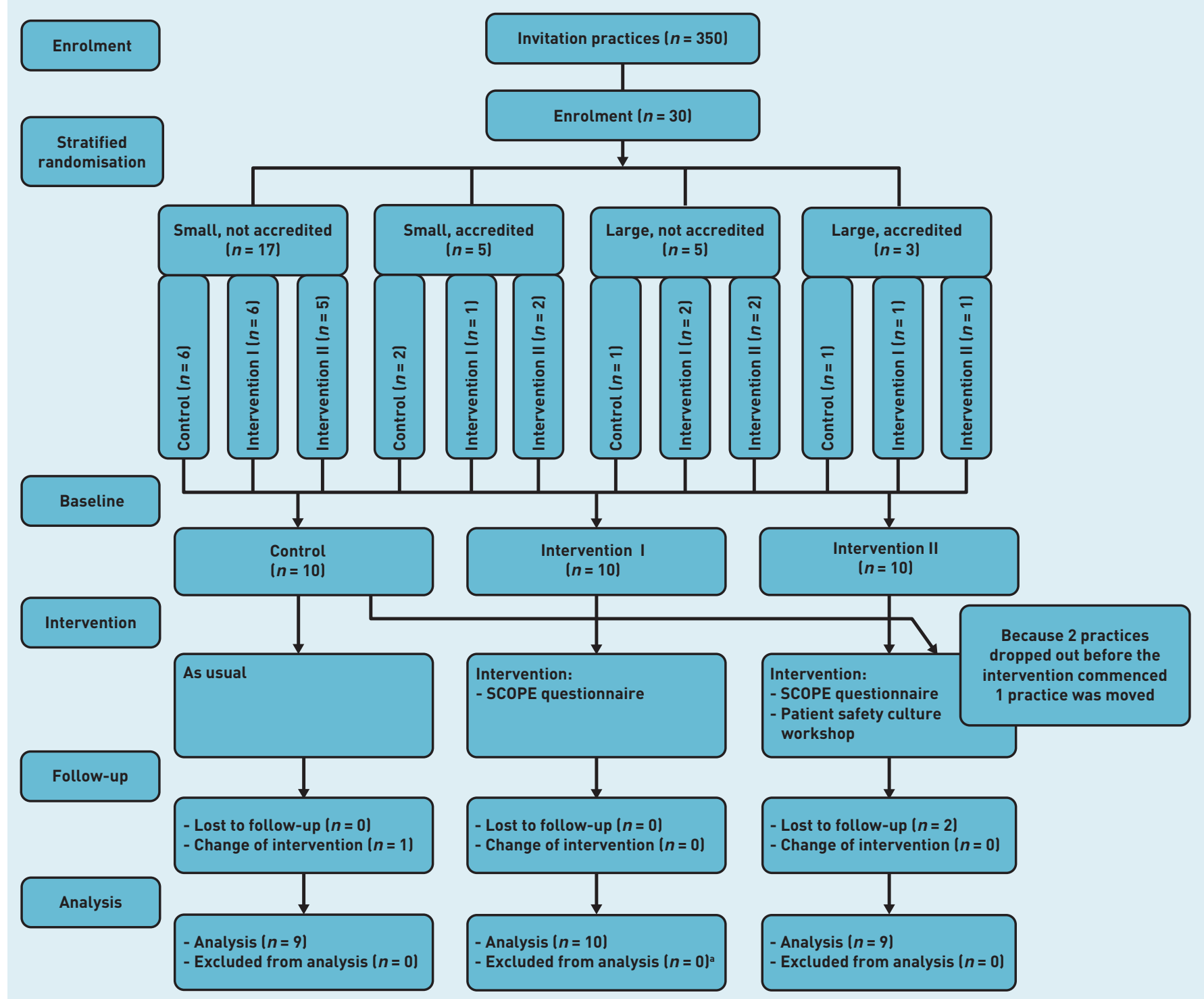

aNone of the practices were excluded in the analysis of the primary outcome; 1 practice in intervention I was excluded in the analyses of the SCOPE questionnaires.

Figure 1. Flowchart enrolment and randomisation.

team meetings [Appendix 2]). Patient safety culture was measured at all practices at follow-up using the SCOPE questionnaire, consisting of 43 items distributed over eight dimensions completed by healthcare staff. SCOPE has sound psychometric properties: Cronbach's $\alpha$ 0.64-0.85.23 Two outcome questions were included: 'Looking back at the past 12 months, how many incidents reports did you fill-out' and 'How would you grade the patient safety in your practice (patient safety grade [PSG]: 5-point scale from 'failing' to 'excellent').

\section{Sample size and practice recruitment}

The sample size was calculated based on the primary outcome, numbers of incident reports, showing 30 practices were needed for a power of 0.90 and an $\alpha$ ) of 0.05 . Based on previous research ${ }^{11}$ an increase from 50 to 70 (intervention I) and 100 (intervention II), respectively, with a standard deviation of 30, was assumed. The outcome was treated as a continuous measure for sample size calculation. Practices ( $n=350$ were invited (February/March 2012) per mail. The first 30 practices that fulfilled inclusion criteria, $\geq 3$ employees and not having completed the culture questionnaire before, were enrolled and allocated to the three research groups $(n=10)$.

\section{Analysis}

The number of incidents was analysed per practice with a generalised linear model using a negative binomial model. Intervention, number of reports at baseline (as natural logarithm), accreditation 


\section{Table 1. Practices and responders characteristics}

\begin{tabular}{|c|c|c|c|}
\hline & Control & Intervention I & Intervention II \\
\hline Composition of staff, \% & $n=67$ & $n=87$ & $n=81$ \\
\hline GPs & 35.8 & 35.6 & 33.3 \\
\hline Assistants & 38.2 & 41.4 & 38.3 \\
\hline Nurses & 17.7 & 19.5 & 27.2 \\
\hline Other & 7.5 & 3.4 & 1.2 \\
\hline Mean age, ${ }^{a}$ years (SD) & 44.6 (9.9) & $44.3(12.4)$ & $41.08(10.7)$ \\
\hline Female sex, a \% & 81.3 & 92.6 & 85.0 \\
\hline Mean years in current practice ${ }^{a}$ (SD) & $7.1(6.3)$ & $9.0(8.6)$ & $8.3(6.2)$ \\
\hline Practices, $n$ & 9 & 10 & 9 \\
\hline \multicolumn{4}{|l|}{ Accreditation status baseline } \\
\hline Yes & 2 & 2 & 3 \\
\hline \multicolumn{4}{|l|}{ Accreditation status follow-up } \\
\hline Yes & 3 & 3 & 4 \\
\hline Working on & 1 & 5 & 2 \\
\hline $\begin{array}{l}\text { Formal reporting system } \\
\text { Baseline (y) }\end{array}$ & 2 & 2 & 4 \\
\hline $\begin{array}{l}\text { Formal reporting system } \\
\text { Follow-up (y) }\end{array}$ & 2 & 4 & 8 \\
\hline
\end{tabular}

$S D=$ standard deviation. $(y)=Y$ es. ${ }^{\text {a Based }}$ on data of the SCOPE questionnaires at follow-up.

Figure 2. Number of incidents by intervention at baseline and follow-up.

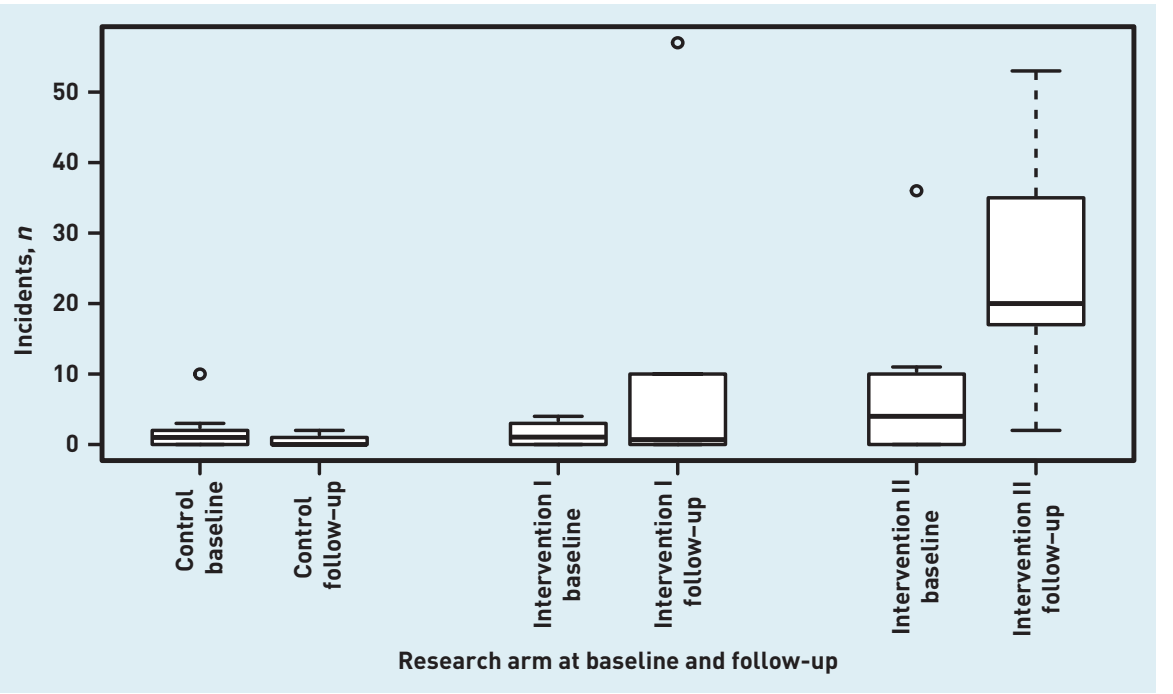

included culture items, sex, discipline and age as predictors. As formal management items could not be answered by everyone, these were not imputed. Therefore, when calculating the mean scores of dimension 7 and 8 one missing was allowed. Percentages positive scores were calculated per dimension. As described in the HSOPS manual, the cut-off value of $>75 \%$ positive scores to indicate practices' strengths and by $\leq 50 \%$ positive scores for weak dimensions were adhered to. ${ }^{29}$ For two measurements in the same practice a $5 \%$ change was considered meaningful. ${ }^{30}$ To analyse differences at follow-up mean dimension scores were calculated. To allow for correlation between staff members within one practice, mixed effects linear regression was performed. Intervention type, practice size, and accreditation status were included in the model. All analyses were conducted in SPSS (version 20.0).

\section{RESULTS}

\section{Participants}

After randomisation, two practices discontinued because of time issues. Therefore one random control practice was moved to intervention II. Table 1 gives an overview of practices and responder characteristics.

\section{Number of incidents}

Intervention I showed an increase of 67 incident reports (15 to 82), intervention II an increase of 154 (70 to 224) and the control group a decrease from 18 to 4 (Figure 2). Appendix 3 shows the distribution of incident reports, reporting procedure, and accreditation status at baseline and follow-up per practice. In intervention I most incidents were reported in three practices, one of these practices was an outlier with 57 reported incidents at follow-up. An employee of this practice participated in a workshop on incident reporting outside this study. An intention to treat analysis showed that intervention II resulted in 42 times $195 \%$ confidence interval $[\mathrm{Cl}]=9.81$ to 177.50 ) more reports than the control group, and intervention I reported 5 times $(95 \% \mathrm{Cl}=1.17$ to 25.49$)$ as much when adjusted for baseline reports, accreditation status and practice size (Table 2). These results did not change relevantly, nor significantly, when analysed without the practice that had been moved from control to intervention II. Without the outlier mentioned above, the effect of intervention I became non-significant. The outcome question on number of reports in the SCOPE questionnaire showed the same 
Table 2. Effect of interventions on number of incidents at follow-up

\begin{tabular}{|c|c|c|c|c|c|c|}
\hline Parameter & $\begin{array}{c}\text { Rate ratio } \\
(95 \% \mathrm{CI})\end{array}$ & $P$-value & $\begin{array}{c}\text { Rate ratio } \\
(95 \% \mathrm{Cl})\end{array}$ & $P$-value & $\begin{array}{c}\text { Rate ratioc } \\
(95 \% \mathrm{CI})\end{array}$ & $P$-value \\
\hline \multicolumn{7}{|c|}{ Intention-to-treat analysis with all 28 practices } \\
\hline Intervention I & 18.45 (4.79 to 71.06$)$ & $<0.001$ & 14.72 (3.72 to 58.20 ) & $<0.001$ & 5.45 (1.17 to 25.49$)$ & 0.03 \\
\hline Intervention II & $56.00(14.47$ to 216.71$)$ & $<0.001$ & 45.47 (11.56 to 178.93$)$ & $<0.001$ & 41.72 (9.81 to 177.50$)$ & $<0.001$ \\
\hline Number of incidents at baseline (ln) & - & - & 1.66 (1.02 to 2.70$)$ & 0.04 & $1.78(1.02$ to 3.10$)$ & 0.04 \\
\hline Accredited at baseline (y) & - & - & - & - & 0.28 (0.08 to 1.03$)$ & 0.06 \\
\hline Practice size in employees & - & - & - & - & $1.22(1.06$ to 1.41$)$ & $<0.01$ \\
\hline \multicolumn{7}{|l|}{ Analysis without outlier in intervention I } \\
\hline Intervention I & 6.25 (1.54 to 25.42$)$ & 0.01 & 6.11 (1.49 to 25.00$)$ & 0.01 & $4.12(0.92$ to 18.44$)$ & 0.06 \\
\hline Intervention || & $56.00(14.47$ to 216.71$)$ & $<0.001$ & 46.50 (11.86 to 182.22$)$ & $<0.001$ & 40.15 (9.88 to 163.10$)$ & $<0.001$ \\
\hline Number of incidents at baseline (ln) & - & - & 1.37 (0.87 to 2.17$)$ & 0.180 & 1.46 (0.87 to 2.46$)$ & 0.15 \\
\hline Accredited at baseline (y) & - & - & - & - & 0.52 (0.14 to 1.92 ) & 0.33 \\
\hline Practice size in employees & - & - & - & - & 1.15 (0.99 to 1.33 ) & 0.07 \\
\hline
\end{tabular}

Intervention I = SCOPE questionnaire. Intervention II = SCOPE questionnaire + workshop. (y) = Yes. ${ }^{a}$ Crude (unadjusted) analysis. ${ }^{b}$ Adjusted for baseline number of incidents (ln = natural logarithm). cAdjusted for baseline number of incidents (ln = natural logarithm), accreditation status and practice size. Values in bold are significant.

trend of increasing reports in intervention II and I, respectively (Appendix 4).

\section{Quality and safety management}

Some indicators showed meaningful changes. Having a formal reporting system remained the same in the control group, but doubled in both intervention groups (I: 2 to 4; II: 4 to 8). In intervention II more practices analysed incidents systematically (2 to 7), had an orientation procedure for new employees ( 3 to 6 ) and patient safety was an agenda item of practices' meetings more often (2 to 8). During the study accreditation status of some practices changed (control: 2 to 3, I: 2 to 3, II: 3 to 4). Particularly in intervention I, practices $(n=5)$ reported at follow-up that they were working towards accreditation.

\section{Patient safety culture}

As part of the intervention, 134 questionnaires were completed at baseline and 183 at follow-up. One practice was excluded from analysis because only one questionnaire was completed at both measurement moments. A total of 131 questionnaires lintervention I median 5, interquartile range [IQR]3-10.5; intervention II median 8, IQR 5.5-11.5) and 168 (control median 5, IQR 3.5-7.5; intervention I median 5, IQR 4-9; intervention II median 7, IQR 4.5-9) questionnaires were included, respectively, as 3 baseline and 15 follow-up questionnaires had $<50 \%$ of safety items completed. A missing analyses showed $2.6 \%$ missing items at baseline and $3 \%$ at follow-up.

Positive scores ranged between 63\% and $86 \%$ at follow-up (Table 3). Several dimensions showed room for improvement
$(<75 \%)$, however, none were below $50 \%$. In intervention I six dimensions improved $\geq 5 \%$, in intervention II three dimensions did. One dimension 'support and fellowship decreased in intervention I. With regard to the PSG, both intervention groups showed rather low scores at baseline. This increased with $8 \%$ and $30 \%$ for intervention I and II, respectively. Multilevel analyses showed no differences between groups at follow-up (Appendix 5).

\section{Course of the workshop in intervention II}

All, but one practice met the minimal attendance, ranging from 4 to 10 staff members (total 66). Workshops proceeded in a pleasant atmosphere and an increased willingness to share opinions and experiences was observed as the workshop progressed. Assigned maturity stages of the participants' own safety culture varied between the first four stages (pathological, reactive, bureaucratic, and proactive). All but one practice drew an action plan, predominantly about introducing or activating a reporting procedure. Evaluation forms showed that, although some staff were sceptic at the start, responses after the workshop were fairly enthusiastic.

\section{DISCUSSION}

\section{Summary}

This study found that administering a safety culture questionnaire solely or integrated in a workshop both increased reporting incidents, however, the effect was much larger in practices receiving the workshop. These practices were also more active in analysing incidents and discussing the subject during team meetings. Increased numbers of reports 
Table 3. SCOPE dimension scores for the control and both intervention groups

\begin{tabular}{|c|c|c|c|c|c|}
\hline Dimensions (scale 1-5) & $\begin{array}{c}\text { Control } \\
\text { (follow-up), } \\
\text { mean (SD) } \\
\% \text { positive } \\
\text { (n=50) }\end{array}$ & $\begin{array}{l}\text { Intervention I } \\
\text { (baseline), } \\
\text { mean (SD) } \\
\% \text { positive } \\
\text { ( } n=59 \text { ) }\end{array}$ & $\begin{array}{l}\text { Intervention I } \\
\text { (follow up), } \\
\text { mean (SD) } \\
\% \text { positive } \\
\text { ( } n=57 \text { ) }\end{array}$ & $\begin{array}{l}\text { Intervention II } \\
\text { (baseline), } \\
\text { mean (SD) } \\
\% \text { positive } \\
\text { [n=72] }\end{array}$ & $\begin{array}{l}\text { Intervention II } \\
\text { (follow-up), } \\
\text { mean (SD) } \\
\% \text { positive } \\
\text { (n=61) }\end{array}$ \\
\hline 1. Handover and teamwork & $\begin{array}{c}3.72 \\
(0.46) \\
69.6 \%\end{array}$ & $\begin{array}{c}3.58 \\
10.67) \\
63.4 \%\end{array}$ & $\begin{array}{c}3.77 \\
(0.49) \\
74.8 \%\end{array}$ & $\begin{array}{c}3.72 \\
(0.48) \\
71.8\end{array}$ & $\begin{array}{c}3.80 \\
(0.37) \\
74.8 \%\end{array}$ \\
\hline 2. Support and fellowship & $\begin{array}{c}4.05 \\
(0.50) \\
85.3 \%\end{array}$ & $\begin{array}{c}3.94 \\
(0.55) \\
82.4 \%\end{array}$ & $\begin{array}{c}3.86 \\
(0.73) \\
75.8 \%\end{array}$ & $\begin{array}{c}3.99 \\
(0.49) \\
82.8 \%\end{array}$ & $\begin{array}{c}4.13 \\
(0.55) \\
83.7 \%\end{array}$ \\
\hline 3. Communication openness & $\begin{array}{c}4.16 \\
(0.51) \\
85.6 \%\end{array}$ & $\begin{array}{c}3.91 \\
(0.70) \\
73.6 \%\end{array}$ & $\begin{array}{c}4.06 \\
(0.49) \\
80.9 \%\end{array}$ & $\begin{array}{c}4.13 \\
(0.57) \\
81.3 \%\end{array}$ & $\begin{array}{c}4.22 \\
(0.43) \\
85.6 \%\end{array}$ \\
\hline 4. Feedback about and learning from error & $\begin{array}{c}3.95 \\
10.84] \\
69.8 \%\end{array}$ & $\begin{array}{c}3.94 \\
(0.86) \\
69.8 \%\end{array}$ & $\begin{array}{c}4.04 \\
(0.65) \\
75.6 \%\end{array}$ & $\begin{array}{c}3.91 \\
(0.77) \\
69.5 \%\end{array}$ & $\begin{array}{c}4.15 \\
(0.61) \\
75.0 \%\end{array}$ \\
\hline 5. Intention to report events & $\begin{array}{c}3.84 \\
10.88) \\
62.6 \%\end{array}$ & $\begin{array}{c}3.76 \\
(1.00) \\
62.7 \%\end{array}$ & $\begin{array}{c}3.90 \\
10.89) \\
68.9 \%\end{array}$ & $\begin{array}{c}3.84 \\
10.931 \\
64.7 \%\end{array}$ & $\begin{array}{c}3.99 \\
(0.71) \\
68.2 \%\end{array}$ \\
\hline $\begin{array}{l}\text { 6. Adequate procedures and } \\
\text { adequate staffing }\end{array}$ & $\begin{array}{c}3.83 \\
(0.49) \\
72.5 \%\end{array}$ & $\begin{array}{c}3.73 \\
(0.56) \\
70.1 \%\end{array}$ & $\begin{array}{c}3.96 \\
(0.45) \\
80.4 \%\end{array}$ & $\begin{array}{c}3.91 \\
(0.54) \\
75.2 \%\end{array}$ & $\begin{array}{c}3.92 \\
(0.54) \\
77.9 \%\end{array}$ \\
\hline $\begin{array}{l}\text { 7. Overall perceptions of patient } \\
\text { safety management }\end{array}$ & $\begin{array}{c}3.66 \\
10.67) \\
65.5 \%\end{array}$ & $\begin{array}{c}3.65 \\
(0.62) \\
64.0 \%\end{array}$ & $\begin{array}{c}3.75 \\
(0.57) \\
69.2 \%\end{array}$ & $\begin{array}{c}3.63 \\
(0.63) \\
61.5 \%\end{array}$ & $\begin{array}{c}3.94 \\
(0.54) \\
84.7 \%\end{array}$ \\
\hline 8. Expectations and actions of managers & $\begin{array}{c}3.71 \\
(0.63) \\
69.9 \%\end{array}$ & $\begin{array}{c}3.68 \\
10.61) \\
66.5 \%\end{array}$ & $\begin{array}{c}3.78 \\
10.54] \\
72.2 \%\end{array}$ & $\begin{array}{c}3.67 \\
(0.59) \\
70.2 \%\end{array}$ & $\begin{array}{c}3.84 \\
(0.50) \\
75.9 \%\end{array}$ \\
\hline Patient safety grade & $\begin{array}{c}3.63 \\
(0.64) \\
58.3 \%\end{array}$ & $\begin{array}{c}3.57 \\
(0.83) \\
61.0 \%\end{array}$ & $\begin{array}{c}3.65 \\
(0.75) \\
69.1 \%\end{array}$ & $\begin{array}{c}3.57 \\
(0.79) \\
54.9 \%\end{array}$ & $\begin{array}{c}3.84 \\
(0.49) \\
85.2 \%\end{array}$ \\
\hline
\end{tabular}

Percentages depicted in bold show differences $\geq 5 \%$. Intervention I = SCOPE questionnaire. Intervention II = SCOPE questionnaire + workshop.

were not perceived as a deterioration of patient safety but contrary, as indicating improved readiness to report incidents that were already present. Therefore, changes in handling incidents may indicate patient safety culture improvement at the practices' 'shop floor' after a team-wise safety culture intervention. However, safety culture measurements did not show large improvements nor differences between the groups after 1 year of follow-up.

\section{Strengths and limitations}

This study is one of the first trials on culture improvement in general practice. Also, to the authors' knowledge it is the first trial that studied the possible effect of a questionnaire and indeed found some effect. However, closer examination revealed that the increase of reporting in intervention I group largely occurred in three practices, of which one had participated in a workshop outside the current study. Excluding this practice resulted in a nonsignificant effect. In the practices that received the workshop the increase in incident reports was found in almost all practices, indicating that the effect was not due to particular practices. Notably, practices that scored high at baseline showed improvement in intervention II. This study has some limitations. First, during the study, quality improvement initiatives emerged, particularly in the questionnaire only group. Five practices appeared to be working on the Dutch practice accreditation system (NHG Praktijk Accreditering ${ }^{\circledR}$ ), which requires an incident reporting system. Further examination showed that the number of incident reports remained the same before and after the intervention indicating that the accreditation process for these five practices did not change their reporting behaviour. However, for future 
studies it would be advisable to include only fully accredited practices to avoid this potential confounder. Second, the absence of changes in culture measurements may be due to underpowering since the sample size calculation was based on the number of incidents, a practice feature. However. the culture questionnaires were conducted at a caregiver level, which resulted in clustered data requiring higher numbers of participants for measuring a potential significant effect. Also, it was not possible to match individual questionnaires before and after. Finally, asking practices to participate voluntarily may have led to selection bias. However, as in real life, such workshops would only be attended on a voluntary basis by interested parties.

\section{Comparison with existing literature}

The MaPSaF, when used in hospitalised settings, showed improvement in culture measurements over a 5-year follow-up. ${ }^{31}$ This study did not find such improvement. Interestingly, using the MaPSaF in general practice Hoffmann et al found effects on incident reporting and not on self-reported culture improvement similar to the current study. ${ }^{32}$ The lack of effect on culture measurements may be explained either by the short intervention time of 1 year or by the insufficient sensitivity of the used survey. ${ }^{33}$ Responsiveness to change should be part of further research.

The workshop was an adapted version of the MaPSaF tool. An important asset of the MaPSaF tool is stimulating participants to self-reflect on daily work within their team. ${ }^{18}$ Team effort seems crucial for patient safety. ${ }^{34-37}$ However, as the MaPSaF is extensive, the SCOPE results were integrated in the workshop, both focusing the discussion and tailoring it to the participating practice. Hereby, the workshop became comprehensive and manageable. Furthermore, an educational part on safety science (such as the state of affairs, terminology, and examples) was added to the workshop. Education is perceived as important in quality improvement ${ }^{38}$ and is the most important factor to improve patient safety in primary care. ${ }^{39}$ The aim was to educate staff on safety science providing them with a sense of urgency concerning safety in general practice, in order to instigate change. In addition, it supported participants' understanding of the systems approach, ensuring a safe atmosphere to discuss culture. With these consecutive elements, the workshops were built on the experiential learning principles of Kolb; for example, concrete experience, reflection, conceptualisation, and experimentation. ${ }^{40}$ The subsequent order of the elements of education and presentation of own practice results (what?), team-based reflection on own practice data (so what?) and teambased development of action plan (now what?) is in line with this experience-based learning cycle ideal for professionals since it explicitly connects daily practice with learning. Moreover, the workshop resulted in an action plan made up by all staff, thus matching their practice with team-based commitment, and increasing the feasibility of actual implementation. ${ }^{41}$ It was found that this format added to the workshop's impact in the current study.

\section{Implications for research and practice}

Applying a culture survey is a convenient way to enhance staff involvement in patient safety culture improvements. However, discussing the results together as a team when embedded in a workshop appeared to be more effective. A step-by-step guide was compiled and, together with the workshop, is freely accessible for all practices. Practices are able to tailor the workshop to their own practice and the workshops can be conducted at relatively low cost and effort. For future research it is worthwhile to study the sustainability of the results found and the need for repeated interventions. An additional challenge is to determine whether practices that changed their behaviour concerning patient safety issues deliver better care than practices that do not invest in patient safety culture change.

not have been conducted. We would like to thank A Steerneman for leading the workshops. Also, we would like to thank Dr NPA Zuithoff for his expertise and contribution to the statistical analysis. We thank the Dutch Practices Accreditation Organization (NHG Praktijk Accreditering ${ }^{\circledR}$ ) for the storage and management of the SCOPE questionnaire data.

\section{Discuss this article}

Contribute and read comments about this article: bjgp.org/letters 


\section{REFERENCES}

1. Kohn L, Corrigan J, Donaldson M. To err is human: building a safer health system. Washington DC: National Academic Press, 2000

2. Sammer CE, Lykens $\mathrm{K}$, Singh KP, et al. What is patient safety culture? A review of the literature. J Nurs Scholarsh 2010; 42(2): 156-165

3. Morello RT, Lowthian JA, Barker AL, et al. Strategies for improving patient safety culture in hospitals: a systematic review. BMJ Qual Saf 2013; 22(1): $11-18$.

4. Weaver SJ, Lubomksi LH, Wilson RF, et al. Promoting a culture of safety as a patient safety strategy. A systematic review. Ann Intern Med 2013; 158(5 Pt 2): 369-374.

5. Verbakel NJ, Langelaan M, Verheij TJ, et al. Improving patient safety culture in primary care: a systematic review. J Patient Saf2014; Mar 18. [Epub ahead of print].

6. Singh $G$, Singh $R$, Thomas EJ, et al. Measuring safety climate in primary care offices. In: Henriksen K, Battles JB, Keyes MA, Grady ML, ed. Advances in patient safety: new directions and alternative approaches (Vol 2: Culture and Redesign). Rockville, MD: Agency for Healthcare Research and Quality, 2008: 59-72.

7. Bodur S, Filiz E. A survey on patient safety culture in primary healthcare services in Turkey. Int J Qual Health Care 2009; 21(5): 348-355.

8. Phipps D, De Bie J, Herborg H, et al. Evaluation of the pharmacy safety climate questionnaire in European community pharmacies. Int J Qual Health Care 2012; 24(1): 16-22.

9. de Wet $\mathrm{C}$, Johnson $\mathrm{P}$, Mash R, et al. Measuring perceptions of safety climate in primary care: A cross-sectional study. J Eval Clin Pract 2012; 18: 135-142.

10. Nordén-Hägg A, Sexton JB, Kälvemark-Sporrong S, et al. Assessing safety culture in pharmacies: the psychometric validation of the Safety Attitudes Questionnaire (SAQ) in a national sample of community pharmacies in Sweden. BMC Clin Pharmacol 2010; 10: 8. doi: 10.1186/1472-6904-10-8.

11. Zwart DLM, Steerneman AHM, van Rensen ELJ, et al. Feasibility of centrebased incident reporting in primary healthcare: the SPIEGEL study. BMJ Qual Saf 2011; 20(2): 121-127.

12. Shojania KG, Thomas EJ. Trends in adverse events over time: why are we not improving? Qual Saf Health Care 2013; 22(4): 273-277.

13. Wagner DB, Spencer JL. The role of surveys in transforming culture. Data, knowledge, and action. In: Kraut Al, ed Organizational surveys: tools for assessment and change. San Francisco, CA: Jossey-Bass Inc, 1996: 67-87.

14. Nieva VF, Sorra J. Safety culture assessment: a tool for improving patient safety in healthcare organizations. Qual Saf Health Care 2003; 12(Suppl II): ii17-23.

15. Wallace LM, Boxall M, Spurgeon P. Barwell F. Organizational interventions to promote risk management in primary care: the experience in Warwickshire, England. Health Serv Manage Res 2007; 20(2): 84-93.

16. Ginsburg L, Norton PG, Casebeer A, Lewis S. An educational intervention to enhance nurse leaders' perceptions of patient safety culture. Health Serv Res 2005; 40(4): 997-1020.

17. Kirk S, Parker D, Claridge $T$, et al. Patient safety culture in primary care: developing a theoretical framework for practical use. Qual Saf Health Care 2007; 16(4): 313-320

18. Wallis K, Dovey S. Assessing patient safety culture in New Zealand primary care: a pilot study using a modified Manchester Patient Safety Framework in Dunedin general practices. J Prim Health Care 2011; 3(1): 35-40.

19. Ashcroft D, Morecroft C. Parker D, Noyce P. Safety culture assessment in community pharmacy: development, face validity, and feasibility of the Manchester Patient Safety Assessment Framework. Qual Saf Health Care 2005 (14:4): 17-21.

20. Mannion R, Konteh FH, Davies HT. Assessing organisational culture for quality and safety improvement: a national survey of tools and tool use. Qual Saf2009; Health Care 18(2): 153-156.

21. Verbakel NJ, Langelaan M, Verheij TJM, et al. Cluster randomized, controlled trial on patient safety improvement in general practice: a study protocol. BMC Fam Pract 2013; 14: 127. doi: 10.1186/1471-2296-14-127.

22. Sorra J, Dyer N. Multilevel psychometric properties of the AHRQ hospital survey on patient safety culture. BMC Health Serv Res 2010; 10: 199. doi: $10.1186 / 1472-6963-10-199$

23. Zwart DLM, Langelaan M, van de Vooren RC, et al. Patient safety measurements in general practice. Clinimetric properties of 'SCOPE'. BMC Fam Pract 2011; 12: 117. doi: 10.1186/1471-2296-12-117.

24. NHG-praktijkaccreditering ${ }^{\circledR}$. Dutch College of General Practice. Practice Quality Accreditation. 2011 http://uww.praktijkaccreditering.n// laccessed 2 Apr 2015).

25. Waring J. Beyond blame: cultural barriers to medical incident reporting. Soc Sci Med 2005: 60(9): 1927-1935.

26. Zwart DLM. Incident reporting in general practice [dissertation]. Utrecht: University Medical Center Utrecht, 2011. http://dspace.library.uu.nl/ handle/1874/205605 laccessed 2 Apr 2015).

27. Gandhi TK, Lee HL. Patient safety beyond the hospital. N Eng J Med 2010; 363(11): 1001-1003

28. Eekhout I, de Vet HC, Twisk JW, et al. Missing data in a multi-item instrument were best handled by multiple imputation at the item score level. J Clin Epidemiol 2014; 67(3): 335-342.

29. Sorra J, Nieva V. Hospital survey on patient safety culture. Rockville, MD Agency for Healthcare Research and Quality, 2004.

30. Sorra J, Famolaro T, Dyer N, et al. Hospital survey on patient safety culture: comparative database report. Rockville, MD: Agency for Healthcare Research and Quality, 2009

31. Ohrn A, Rutberg H, Nilsen P. Patient safety dialogue: evaluation of an intervention aimed at achieving an improved patient safety culture. J Patient Saf $2011 ; \mathbf{7 ( 4 ) :}$ 185-912.

32. Hoffmann B, Müller V, Rochon J, et al. Effects of a team-based assessmen and intervention on patient safety culture in general practice: an open randomised controlled trial. BMJ Qual Saf2013; 23(1): 35-46.

33. Guldenmund FW. The nature of safety culture: a review of theory and research. Saf Sci2000: 34(1-3): 215-257.

34. Weaver SJ, Dy SM, Rosen MA. Team-training in healthcare: a narrative synthesis of the literature. BMJ Qual Saf 2014; 23(5): 359-372.

35. Pettker CM, Thung SF, Raab CA, et al. A comprehensive obstetrics patient safety program improves safety climate and culture. Am J Obstet Gynecol 2011; 204(3): 216, e1-eb.

36. Rabøl LI, Østergaard D, Mogensen T. Outcomes of classroom-based team training interventions for multiprofessional hospital staff. A systematic review. Qual Saf Health Care 2010; 19(6): e27.

37. Jones KJ, Skinner AM, High R, Reiter-Palmon R. A theory-driven, longitudinal evaluation of the impact of team training on safety culture in 24 hospitals. BMJ Qual Saf 2013; 22(5): 394-404

38. Conry MC, Humphries N, Morgan K, et al. A 10 year (2000-2010) systematic review of interventions to improve quality of care in hospitals. BMC Health Serv Res 2012: 12: 275. doi: 10.1186/1472-6963-12-275.

39. Gaal S, Verstappen W, Wensing M. What do primary care physicians and researchers consider the most important patient safety improvement strategies? BMC Health Serv Res 2011;11: 102.

40. Kolb DA. Experiential learning: experience as the source of learning and development. Upper Saddle River, NJ: Prentice-Hall, 1984.

41. Grol R, Grimshaw J. From best evidence to best practice: effective implementation of change in patients' care. Lancet 2003; 362: 1225-1230. 


\section{Appendix 1. Workshop programme}

- Introduction to patient safety

- Discussing patient safety terminology

- Data on number of incidents internation-

ally and nationally

- Human factor engineering

- Why do people make mistakes?

- Interactive examples

-System approach

- Classify organisation according to the MaP-

$\mathrm{SaF}$ vignettes on two dimensions (individually)

- Each responder classified the maturity

of their practice for two dimensions without consultation

- Patient safety culture

- Theory on patient safety culture

- Feedback on SCOPE questionnaire

- Discussion about results

- Dialogue about own patient safety culture based on vignettes

- Vignettes are discussed in pairs of same discipline

- Vignettes are discussed with all staff

- Discussion on possible improvement actions

- Drafting of practice improvement action plan

- Evaluation and take home message

\section{Appendix 2. Quality and safety management questions}

The following questions were included in the quality and safety form conducted at baseline and follow-up Incident reporting

1. How many incidents from your practice are known from $2011 / 2012$ ? (primary outcome)

2. In which way became these known by you?

3. If your practice has a formal reporting system, since when was this used?

4a. How many of these incidents have you analysed?

4b. Which method was used?

5. How many of these incidents caused harm to patients?

6. Of these incidents, how many were, to your opinion, possible avoidable?

7. Did you proactively searched for incidents in your practice? (for example by file studies, audits, reporting weeks)

8a. Were there improvement actions implemented in response to (reported) incidents?

$8 \mathrm{~b}$. If yes, did these improvement actions lead to the desired results?

A. Complaints procedure

1. How many complaints were received the past year (both from employees and patients)?

2. Does your practice have an internal coordinator for complaints?

3. Is there a formal procedure for handling of complaints?

B. Team meetings

1. Was the subject patient safety on the agenda for planned team meetings the past year (2011/2012)?

2. If yes, please specify dates on which patient safety was on the agenda.

3. Was patient safety during these team meetings actually discussed?

4. Have there been team meetings in $2011 / 2012$ where patient safety was not on the agenda but was discussed?

5. Could you describe in catchwords the content of the discussed subject? (or sent minutes)

6a. Were action points/improvement plans formulated during these meetings? If yes, could you describe these in catchwords.

6b. If yes, were these action points/improvement plans actually implemented and evaluated? Which were and which were not? If no, why not?

\section{Training}

1. Was the subject patient safety subject of training the past year?

2. Which training was this?

3. Was this training for the whole practice or individual?

4. Did you notice the learned being implemented in practice? If no, why not?

D. Safety management

1. Does your practice have an patients safety management plan or otherwise described safety management policy?

2a. Is this practice safety plan deployed the last year?

2b. If not, why not/which subparts were not?

E. Quality management

1. Does your practice have a protocols book?

2. Do you participate regularly in pharmacotherapeutic consultations?

3. Do you have a procedure/method for controlling the content of the GP emergency bag? (inclusive medication)

4. Does your practice have an introduction procedure for new employees?

5. Does your practice have an emergency telephone?

6. Have you ever conducted a patient safety satisfaction survey?

7. Does your practice use 'ZorgDomein' (This is a referral aid for physicians)

8. Does your practice have a procedure to check repeat prescriptions?

9. When was the last time the equipment in the practice was calibrated?

10. Did you implement a quality improvement project last years? 


\begin{tabular}{|c|c|c|c|c|c|c|}
\hline Intervention & $\begin{array}{l}\text { Incidents } \\
\text { baseline, } n\end{array}$ & $\begin{array}{c}\text { Incidents } \\
\text { follow-up, } n\end{array}$ & $\begin{array}{c}\text { Formal } \\
\text { reporting } \\
\text { procedure baseline }\end{array}$ & $\begin{array}{c}\text { Formal } \\
\text { reporting } \\
\text { procedure follow-up }\end{array}$ & $\begin{array}{c}\text { Accreditation } \\
\text { status } \\
\text { baseline }\end{array}$ & $\begin{array}{c}\text { Accreditation } \\
\text { status } \\
\text { follow-up }\end{array}$ \\
\hline Control & 2 & 2 & Yes & Yes & No & Yes \\
\hline Control & 2 & 0 & No & - & No & No \\
\hline Control & 0 & 0 & No & No & No & No \\
\hline Control & 0 & 0 & No & Yes & Yes & Yes \\
\hline Control & 0 & 0 & No & No & Yes & Yes \\
\hline Control & 3 & 1 & Yes & - & No & In progress \\
\hline Control & 1 & 1 & No & No & No & No \\
\hline Control & 10 & 0 & No & No & No & No \\
\hline Control & 0 & 0 & No & No & No & No \\
\hline SCOPE & 0 & 0 & No & No & No & In progress \\
\hline SCOPE & 0 & 0 & No & No & No & In progress \\
\hline SCOPE & 1 & 1 & No & No & No & In progress \\
\hline SCOPE & 0 & 0 & No & - & No & In progress \\
\hline SCOPE & 3 & 10 & Yes & Yes & Yes & Yes \\
\hline SCOPE & 4 & 57 & No & Yes & No & Yes \\
\hline SCOPE & 0 & 0 & No & Yes & Yes & Yes \\
\hline SCOPE & 1 & 10 & No & No & No & No \\
\hline SCOPE & 3 & 0 & No & No & No & No \\
\hline Workshop & 0 & 5 & No & Yes & No & In progress \\
\hline Workshop & 5 & 20 & Yes & Yes & Yes & Yes \\
\hline Workshop & 10 & 20 & Yes & Yes & Yes & Yes \\
\hline Workshop & 0 & 20 & No & Yes & No & No \\
\hline Workshop & 36 & 53 & Yes & Yes & No & Yes \\
\hline Workshop & 11 & 35 & Yes & Yes & Yes & Yes \\
\hline Workshop & 4 & 17 & No & Yes & No & No \\
\hline Workshop & 0 & 52 & No & Yes & No & No \\
\hline
\end{tabular}

\section{Appendix 4. Self-reported number of incident forms loutcome question included in the SCOPE questionnaire)}

\begin{tabular}{|c|c|c|c|c|}
\hline \multirow[b]{2}{*}{ Intervention, $n$} & \multicolumn{2}{|c|}{ Baseline } & \multicolumn{2}{|c|}{ Follow-up } \\
\hline & Frequency & $\%$ & Frequency & $\%$ \\
\hline \multicolumn{5}{|l|}{ Controla $^{a}$} \\
\hline None & & & 40 & 83.3 \\
\hline $1-2$ & & & 3 & 6.3 \\
\hline $3-5$ & & & 4 & 8.3 \\
\hline $6-10$ & & & - & - \\
\hline $11-20$ & & & - & - \\
\hline$>20$ & & & 1 & 2.1 \\
\hline \multicolumn{5}{|c|}{ SCOPE (intervention I) } \\
\hline None & 49 & 84.5 & 34 & 61.8 \\
\hline $1-2$ & 7 & 12.1 & 7 & 12.7 \\
\hline $3-5$ & 1 & 1.7 & 4 & 7.3 \\
\hline $6-10$ & 1 & 1.7 & 6 & 10.9 \\
\hline $11-20$ & - & - & 4 & 7.3 \\
\hline$>20$ & - & - & - & - \\
\hline \multicolumn{5}{|c|}{ SCOPE + workshop (intervention II) } \\
\hline none & 56 & 77.8 & 21 & 35.0 \\
\hline $1-2$ & 9 & 12.5 & 11 & 18.3 \\
\hline $3-5$ & 7 & 9.7 & 17 & 28.3 \\
\hline $6-10$ & - & - & 9 & 15.0 \\
\hline $11-20$ & - & - & 2 & 3.3 \\
\hline$>20$ & - & - & - & - \\
\hline
\end{tabular}




\section{Appendix 5. Effect of interventions on SCOPE safety culture dimensions after 1 year of follow-up}

\begin{tabular}{|c|c|c|c|c|}
\hline & $\begin{array}{l}\text { Regression coefficient } \\
\qquad(95 \% \mathrm{CI})^{\mathrm{a}}\end{array}$ & $P$-value & $\begin{array}{l}\text { Regression coefficient } \\
\qquad(95 \% \mathrm{CI})^{\mathrm{b}}\end{array}$ & $P$-value \\
\hline \multicolumn{5}{|c|}{ 1. Handover and teamwork } \\
\hline Intervention | & $0.031(-0.20$ to 0.27$)$ & 0.796 & $0.072(-0.15$ to 0.30$)$ & 0.531 \\
\hline Intervention || & $0.087(-0.14$ to 0.31$)$ & 0.449 & $0.123(-0.09$ to 0.34$)$ & 0.254 \\
\hline Accredited (y) & & & $-0.039(-0.25$ to 0.17$)$ & 0.716 \\
\hline Practice size & & & $-0.024(-0.05$ to 0.00$)$ & 0.069 \\
\hline \multicolumn{5}{|c|}{ 2. Support and fellowship } \\
\hline Intervention | & $-0.216(-0.52$ to 0.09$)$ & 0.164 & $-0.224(-0.54$ to 0.09$)$ & 0.160 \\
\hline Intervention || & $0.065(-0.24$ to 0.37$)$ & 0.674 & $0.076(-0.23$ to 0.38$)$ & 0.625 \\
\hline Accredited (y) & & & $-0.201(-0.50$ to 0.10$)$ & 0.193 \\
\hline Practice size & & & $-0.002(-0.04$ to 0.03$)$ & 0.089 \\
\hline \multicolumn{5}{|c|}{ 3. Communication openness } \\
\hline |ntervention | & $-0.170(-0.46$ to 0.35$)$ & 0.245 & $-0.144(-0.43$ to 0.14$)$ & 0.323 \\
\hline Intervention || & $0.064(-0.22$ to 0.35$)$ & 0.660 & 0.102 (-0.18 to 0.38$)$ & 0.479 \\
\hline Accredited (y) & & & $-0.113(-0.39$ to 0.16$)$ & 0.425 \\
\hline Practice size & & & $-0.019(-0.05$ to 0.02$)$ & 0.279 \\
\hline \multicolumn{5}{|c|}{ 4. Feedback about and learning from error } \\
\hline |ntervention | & $-0.024(-0.41$ to 0.36$)$ & 0.902 & $0.030(-0.32$ to 0.38$)$ & 0.866 \\
\hline Intervention || & $0.102(-0.28$ to 0.48$)$ & 0.602 & $0.177(-0.16$ to 0.52$)$ & 0.308 \\
\hline Accredited (y) & & & $-0.317(-0.65$ to 0.02$)$ & 0.064 \\
\hline Practice size & & & $-0.028(-0.07$ to 0.01$)$ & 0.177 \\
\hline \multicolumn{5}{|c|}{ 5. Intention to report events } \\
\hline |ntervention | & $0.051(-0.35$ to 0.45$)$ & 0.800 & $0.064(-0.34$ to 0.45$)$ & 0.746 \\
\hline |ntervention || & $0.148(-0.24$ to 0.54$)$ & 0.455 & $0.168(-0.20$ to 0.54$)$ & 0.368 \\
\hline Accredited (y) & & & $-0.327(-0.66$ to 0.00$)$ & 0.053 \\
\hline Practice size & & & $-0.015(-0.06$ to 0.03$)$ & 0.712 \\
\hline \multicolumn{5}{|c|}{ 6. Adequate procedures and adequate staffing } \\
\hline Intervention I & $0.075(-0.26$ to 0.41$)$ & 0.663 & $0.083(-0.27$ to 0.44$)$ & 0.459 \\
\hline Intervention || & $0.123(-0.21$ to 0.46$)$ & 0.474 & $0.135(-0.22$ to 0.49$)$ & 0.459 \\
\hline Accredited (y) & & & $-0.002(-0.35$ to 0.35$)$ & 0.992 \\
\hline Practice size & & & $-0.001(-0.05$ to 0.04$)$ & 0.766 \\
\hline \multicolumn{5}{|c|}{ 7. Overall perceptions of patient safety management } \\
\hline Intervention | & 0.017 (-0.33 to 0.37) & 0.922 & $0.024(-0.34$ to 0.39$)$ & 0.895 \\
\hline Intervention II & $0.218(-0.13$ to 0.57$)$ & 0.211 & $0.237(-0.12$ to 0.60$)$ & 0.189 \\
\hline Accredited (y) & & & $-0.122(-0.48$ to 0.23$)$ & 0.486 \\
\hline Practice size & & & $-0.007(-0.05$ to 0.04$)$ & 0.736 \\
\hline \multicolumn{5}{|c|}{ 8. Expectations and actions of managers } \\
\hline Intervention I & $0.001(-0.37$ to 0.37$)$ & 0.997 & $0.015(-0.38-0.41)$ & 0.936 \\
\hline Intervention || & $0.133(-0.24$ to 0.50$)$ & 0.468 & $0.156(-0.24-0.55)$ & 0.418 \\
\hline Accredited (y) & & & $-0.050(-0.44-0.34)$ & 0.791 \\
\hline Practice size & & & $-0.011(-0.06-0.04)$ & 0.633 \\
\hline \multicolumn{5}{|c|}{ Patient safety grade } \\
\hline Intervention I & $-0.035(-0.48$ to 0.42$)$ & 0.875 & $-0.008(-0.44-0.42)$ & 0.970 \\
\hline Intervention || & $0.161(-0.29$ to 0.61$)$ & 0.463 & $0.224(-0.20-0.65)$ & 0.287 \\
\hline Accredited (y) & & & $-0.344(-0.76-0.08)$ & 0.103 \\
\hline Practice size & & & $-0.022(-0.07-0.03)$ & 0.386 \\
\hline
\end{tabular}

Intervention I = SCOPE questionnaire. Intervention II = SCOPE questionnaire + workshop. (y) = Yes. ${ }^{a}$ Crude (unadjusted) analyses. ${ }^{b}$ Adjusted for accreditation status and practice size. 